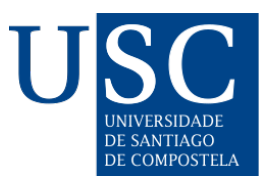

Dereito: revista xurídica da Universidade de Santiago de Compostela, 30(2), 2021. ISSN-e: 2174-0690

https://doi.org/10.15304/dereito.30.1.7929

Recensiones

\title{
FALCón Y TELLA, María José: Cuestiones de Filosofía del Derecho, Madrid, Marcial Pons, 2020, pp. 116
}

\author{
María de los Ángeles Nogales Naharro', a \\ ${ }^{1}$ Profesora de Filosofía del Derecho Universidad Católica “Santa Teresa de Jesús” de Ávila, España \\ a marian.nogales@ucavila.es
}

La última obra publicada de la profesora $\mathrm{M}^{\mathrm{a}}$ José Falcón y Tella con el título de Cuestiones de Filosofía del Derecho recoge de forma clara, concisa y con un carácter eminentemente didáctico y pedagógico un compendio depurado de aquellas cuestiones esenciales y relevantes para la Filosofía del Derecho que, por otra parte han sido objeto de un minucioso estudio y profundo análisis por parte de la autora puesto de relieve en prestigiosas publicaciones anteriores.

Como no podía ser de otro modo tratándose de nuestra autora, en esta obra también muestra su compromiso jurídico con la sociedad al entrar a analizar cuestiones prácticas que revelan los desafíos que se presentan a la Ciencia del Derecho en un momento político y social convulso que demanda una respuesta clarificadora sobre la propia esencia, metodología y finalidad del Derecho. Por ello la pertinencia de la aparición de esta obra en el actual panorama filosófico-jurídico español es incontestable.

Dada la riqueza y variedad de los temas tratados destacaremos para el lector, a título de botón de muestra algunos de los aspectos que consideramos más relevantes.

La obra que consta de siete capítulos comienza a modo de síntesis de manera rigurosa, clara y sistemática el análisis del concepto del Derecho y destaca la autora por su brillantez expositiva y clarificadora en el método tridimensional desde un punto de vista formal en el estudio del mismo. El Derecho constituye una integración normativa de hechos según valores. Así la Teoría tridemensional del Derecho, de la cual la autora es exponente cualificada, se presenta como asunción ontológica sobre el fenómeno jurídico general.

Desde esta Teoría se concibe el campo de estudio disciplinar del Derecho como realidad tridimensional y, verifica la fructífera utilidad que la naturaleza tripartita del Derecho ofrece tanto para la elaboración de cualquier análisis sincrónico del Derecho a los efectos de construir pedagógicamente una teoría explicativa del Derecho como para conducir metodológicamente determinadas investigaciones sectoriales de las cuales también se ocupa a lo largo de la obra.

El capítulo segundo profundiza en el concepto de validez del derecho y la forma de establecer las bases del mismo, su fundamento, desde el enfoque tridimensional. Confirmando que en el problema de la validez del derecho se da tres dimensiones de un mismo problema. Conceptos como legitimidad, validez y eficacia son expuestos y tratados con rigurosidad científica y claridad expositiva; al tiempo que delimita conceptos anexos como son la noción de legalidad, la coactividad, la juridicidad y la eficiencia. 
El capítulo tercero de la obra lo dedica a la desobediencia ante la ley injusta. Conociendo la trayectoria investigadora de la autora, su amplio bagaje en el tema de la desobediencia civil que la ha constituido en un citado referente a nivel internacional, su dedicación en la vida académica, el lector de esta obra encontrará en este epígrafe, de forma clara, extensa, profunda y de amena lectura lo más original de las conclusiones alcanzadas en los estudios anteriores sobre esta materia. No obstante, no nos resistimos a mostrar un esbozo del mismo.

La posición de la profesora Ma José Falcón y Tella respecto a la desobediencia civil, apuntada en esta obra, consiste en afirmar la existencia de un cierto «derecho a la desobediencia civil». No sólo un derecho de carácter moral, sino un cierto «derecho subjetivo».

Desde el esquema tridemensional que la mayoría de los autores siguen para la justificación de la desobediencia civil la autora señala que siempre que se den todos los requisitos de la misma, ésta puede resultar: 1- «justificada» en el plano de los valores: y analiza ampliamente y detalladamente la justificación moral desde las doctrinas iusnaturalistas, relativistas o utilitarista. 2- «Explicada» en el nivel de los hechos y 3- «Excusada» en el ámbito de las normas jurídicas.

En este tercer miembro -en el de las normas jurídicas-, y en la diferencia entre justificar y excusar -la excusa jurídica-, la autora apunta el talón de Aquiles o el filón sin explotar que permitiría hablar de un «derecho», «sui generis» a desobedecer civilmente, destacando en esta temática una palabra clave «antinomias» que nosotros hemos traducido en el contexto por contradicción o conflicto.

En la presente obra, la autora tras exponer brevemente la distinción entre antinomias y "pugna de deberes" se pregunta si cabe la objeción de conciencia del juez ante la ley injusta o podría ser un supuesto de desobediencia civil, analiza y argumenta con claridad lógica, la función del juez y los principios que le vinculan así como las posibilidades que al mismo se le ofrece.

Especial interés despierta también al lector el capítulo cuarto dedicado a un tema nuclear en la Filosofía del Derecho, el tema de la Justicia, al cual la profesora Má José Falcón y Tella ha dedicado a lo largo de su amplia trayectoria académica y bagaje investigador sus mejores esfuerzos haciéndose partícipe de un conocimiento privilegiado en este tema y obteniendo óptimos resultados avalado por prestigiosas publicaciones. En esta obra recoge de manera ordenada, coherente y concisa lo más granado de su saber.

Desde un enfoque multidisciplinar, el lector encontrará un compendio de las principales doctrinas teóricas, desde las denominadas clásicas hasta las más actuales, dando respuesta a los interrogantes que han girado en torno a la idea, concepto, fundamento, clases y positivación de la justicia. Mención especial requiere el análisis y exposición que la profesora Ma José realiza sobre la justicia como teoría del mérito. Cuestión sobre la cual ha disertado en anteriores estudios científicos con una profundidad y análisis dialéctico que la ha hecho merecedora de un reconocimiento singular.

Los capítulos siguientes se presentan al lector como cuestiones o áreas temáticas conexas al tema de la justicia y los dedica desde la perspectiva de estudio y método de la tridemensionalidad a la teoría del castigo (capítulo 5); la guerra justa (capítulo 6) y para finalizar una sugerente disertación sobre la justicia, tolerancia y sociedad abierta (capítulo7). El lector encontrará en estos capítulos una atractiva invitación a dar respuesta, acompañando a la autora en su análisis crítico, a cuestiones tales como si es justa la pena capital; si se puede hablar de una guerra justa en Irak o la cuestión de la tolerancia en relación con las actuaciones del poder político en una sociedad plural. En la exposición de estos temas la autora destaca por haber sabido conciliar el rigor científico y metodológico con que analiza los diversos y muy complejos problemas y la claridad expositiva, al tiempo que incita a reflexionar y a agudizar el sentido crítico libre de prejuicios. 
La nueva obra concluye con una abundante y seleccionada bibliografía que da muestras del gran valor científico de la misma y del rigor intelectual en su autora.

Se trata de una obra bien documentada, sólida y profunda en las cuestiones que plantea, concreta y clara en la exposición, amena en su lectura, de la cual el lector podrá sacar provecho y enriquecerse del compendio que la profesora María José Falcón y Tella ha realizado en el estudio de cuestiones nucleares para el Derecho y relevantes para la justicia en un contexto histórico actual, que demanda de los académicos claridad y certeza con rigor científico y honestidad intelectual, por ello esta obra resulta de gran interés para todos aquellos estudiosos de la Filosofía del Derecho. 